Rio de Janeiro. Ano 10. Volume 17. Número 1. Janeiro a Junho de 2016

Periódico Semestral da Pós-Graduação Stricto Sensu em Direito Processual da UERJ

Patrono: José Carlos Barbosa Moreira. ISSN 1982-7636. pp. 02-06

http://www.e-publicacoes.uerj.br/index.php/redp/index

\title{
ACORDO DE COOPERAÇÃO PREMIADA. QUAIS SÃO OS LIMITES? ${ }^{1}$
}

\section{PLEA BARGAINING IN BRAZIL: WHAT ARE ITS LIMITS?}

\section{Afranio Silva Jardim}

Professor Associado de Direito Processual Penal da UERJ. Mestre e Livre-Docente em Direito Processual Penal. Procurador de Justiça (aposentado) no ERJ. caniljardimsilva@caniljardimsilva.com

RESUMO: O presente estudo almeja analisar o instituto do acordo de cooperação premiada de forma crítica, examinando especialmente os limites à sua adoção.

PALAVRAS-CHAVE: Cooperação premiada; Limites; Legalidade; Direito Processual Penal.

ABSTRACT: The present study aims to critically analyze plea bargaining in Brazil, with special concern to its limits of application.

KEYWORDS: Plea bargaining; Limits; Legality; Brazilian Criminal Procedure Law.

Ultimamente, tenho me ocupado com a extensão dos acordos de cooperação premiada (delação premiada), segundo noticiado pela imprensa e publicado em sites jurídicos especializados. Tenho me preocupado com a visão privatista e pragmática que vem grassando em nosso sistema processual penal. Daí, por que volto ao tema, com abordagens diferentes.

\footnotetext{
${ }^{1}$ Artigo recebido em 22/05/2016, sob dispensa de revisão.
} 
Revista Eletrônica de Direito Processual - REDP.

Rio de Janeiro. Ano 10. Volume 17. Número 1. Janeiro a Junho de 2016

Periódico Semestral da Pós-Graduação Stricto Sensu em Direito Processual da UERJ

Patrono: José Carlos Barbosa Moreira. ISSN 1982-7636. pp. 02-06

http://www.e-publicacoes.uerj.br/index.php/redp/index

É imperioso reconhecer que o acordo de cooperação premiada é um negócio processual e, por conseguinte, regido pelas regras e princípios de Direito Público. Como é de todos sabido, as regras e princípios do Direito Penal e do Direito Processual Penal são cogentes e ficam fora do poder dispositivo das partes que atuam no processo penal. Como se costuma dizer, em termos de Direito Privado, pode-se fazer tudo o que não seja proibido, enquanto sob a égide do Direito Público, só se fazer o que seja expressamente permitido ...

Nada obstante, estas premissas comezinhas, temos notícia de acordos de cooperação premiada que, em muito, extrapolam os limites jurídicos razoáveis, transformando regras do Direito Penal e Processual penal em objeto de negociação entre um órgão do Ministério Público e um "criminoso" (usei a expressão mais forte, porque o indiciado ou acusado confessa crimes e deve ser membro de uma organização criminosa). Vale dizer, estão negociando com regras imperativas e de aplicação obrigatória, caras à própria ideia de sistema. Desta forma, procuramos abaixo estabelecer alguns limites a estes acordos, partindo sempre da premissa acima explicitada.

Em trabalho anterior, apresentado ao XXI Congresso do Ministério Público, realizado no ano passado, na cidade do Rio de Janeiro, sustentamos que o Ministério Público não pode oferecer ao delator "prêmio" que não esteja expressamente previsto na lei específica. Tal limitação se refere não só ao tipo de benefício (prêmio), como também se refere à sua extensão, mesmo que temporal. Assim, o membro do Ministério Público não pode oferecer ao indiciado ou réu algo que importe em "afastamento" do Código Penal, Lei de Execução Penal ou Código de Processo Penal. Esta manifestação de vontade não pode se colocar acima do nosso sistema processual.

Destarte, o Poder Judiciário não deve homologar acordos de cooperação que consagrem "prêmios" não autorizados na lei cogente e, com mais razão, que contrariem tal lei. Não devem ser homologadas "delações premiadas" que prevejam cumprimento de penas altas em regimes não permitidos pela lei penal ou de execução penal, prisão domiciliar para penas de dez anos, bem como não deve ser homologada suspensão de processos penais para não aumentar penas já aplicadas, renúncias prévias do Ministério Público a eventuais e futuros recursos ou renúncia à propositura de futuras ações penais ou cíveis, etc., etc. 
Revista Eletrônica de Direito Processual - REDP.

Rio de Janeiro. Ano 10. Volume 17. Número 1. Janeiro a Junho de 2016

Periódico Semestral da Pós-Graduação Stricto Sensu em Direito Processual da UERJ

Patrono: José Carlos Barbosa Moreira. ISSN 1982-7636. pp. 02-06

http://www.e-publicacoes.uerj.br/index.php/redp/index

Já na perspectiva dos indiciados ou réus, cabem algumas restrições e ponderações. Primeiro, os investigados só podem eficazmente se comprometer a deveres ou obrigações que se insiram no seu poder de disponibilidade. Evidentemente, direitos indisponíveis não podem ser objeto de "negociação". Por conseguinte, seria nula qualquer cláusula que vedasse ao indiciado o direito de exercer, futuramente, o seu direito de ação, mormente em se tratando de Habeas Corpus, como seria também inválida a renúncia prévia ao duplo grau de jurisdição.

Agora trazemos à consideração da doutrina e jurisprudência uma questão que tem sido descurada até o presente momento: se é certo que, em se tratando de direito disponível, o indiciado ou réu pode assumir qualquer obrigação ou dever, através de cláusulas constantes do acordo de cooperação premiada, também é certo que o dever previsto na lei específica é colaborar efetivamente com a investigação criminal, sob pena de não se beneficiar com os benefícios legais estipulados.

Sustentamos que o descumprimento, por parte do indiciado ou réu, de obrigações outras que não o dever de colaborar, não pode importar na "quebra da delação premiada". Em outras palavras, se o colaborador não colaborar com a investigação da organização criminosa, não gozará de qualquer benefício legal estipulado no negócio jurídico processual. Não pode ele mentir ou omitir fatos relevantes que sabe e que tenham relevância para o inquérito ou processo penal. Agora, se o indiciado ou réu efetivamente colaborar, mas descumprir uma obrigação ou dever estranha à própria investigação, não pode ser privado dos prêmios legalmente previstos no acordo de "delação premiada".

Note-se que, evidentemente, outras consequências jurídicas podem penalizar aqueles que não adimpliram as obrigações assumidas, desde que tais consequências não afastem os benefícios pela colaboração feita. Pomos um exemplo bizarro: se o réu deixar de dar assistência econômica a uma vítima do crime, descumprindo uma cláusula neste sentido constante do acordo de "delação premiada", não pode deixar de se beneficiar dos prêmios legalmente prometidos, caso tenha realmente colaborado com as investigações. Tal omissão 
Revista Eletrônica de Direito Processual - REDP.

Rio de Janeiro. Ano 10. Volume 17. Número 1. Janeiro a Junho de 2016

Periódico Semestral da Pós-Graduação Stricto Sensu em Direito Processual da UERJ

Patrono: José Carlos Barbosa Moreira. ISSN 1982-7636. pp. 02-06

http://www.e-publicacoes.uerj.br/index.php/redp/index

pode ser considerada na aplicação da pena base, mas não importa em "quebra" do acordo de colaboração.

Ademais, o indiciado ou réu só terá direito ao benefício legal, constante do acordo de cooperação premiada, se ajudar a investigação do crime de organização criminosa e dos crimes praticados por esta organização. O "prêmio" previsto no acordo não fica dependente da ajuda do colaborador na investigação de outras organizações criminosas ou de outros crime estranhos ao seu inquérito ou processo. Lógico que tais informações podem ser bem vindas, entretanto, não devem ser objeto do acordo de colaboração. Caso conste do acordo, não deve o indiciado ou réu perder o "prêmio" se deixar de colaborar com a apuração daqueles outros crimes, que não estão sendo objeto da investigação onde se deu a delação premiada.

Uma última advertência: esta amplitude de negociação (a nosso juízo, ilegal) pode até mesmo fragilizar o membro do Ministério Público, principalmente aquele que atua em comarcas distantes dos grandes centros. O crime organizado, o poder econômicos e o poder político podem pressionar o promotor ou procurador, constrangê-lo e até ameaça-lo para que determinado indiciado ou réu seja favorecido no acordo de cooperação premiada. Sabendo que o membro do Ministério Público pode conceder benefícios ao seu talante, fica ele exposto a todo tipo de ingerência; ao menos o cidadão comum tem o direito de suspeitar disso ...

Por ser um instituto relativamente novo em nosso sistema jurídico e, tendo em vista o grande apoio popular à atual apuração dos crimes de corrupção em nosso país, avaliamos que os tribunais estão muito cautelosos no enfrentamento destas questões, mormente diante de lacunas na doutrina sobre estes temas mais específicos.

O meu temor é que alguns exemplos equivocados da chamada "operação Lava-Jato", segundo o que vem sendo veiculado pela imprensa, sejam disseminados por todo o nosso extenso território. Temo que o Direito Penal resulte fragmentado e com aplicação insólita pelos vários órgãos jurisdicionais de nosso pais. Temo que a aplicação uniforme das regras do nosso sistema penal fique na dependência da vontade de um Promotor de Justiça e de um 
Revista Eletrônica de Direito Processual - REDP.

Rio de Janeiro. Ano 10. Volume 17. Número 1. Janeiro a Junho de 2016

Periódico Semestral da Pós-Graduação Stricto Sensu em Direito Processual da UERJ

Patrono: José Carlos Barbosa Moreira. ISSN 1982-7636. pp. 02-06

http://www.e-publicacoes.uerj.br/index.php/redp/index

"criminoso" ... A este nível de privatização das regras de Direito Público não podemos

chegar, tornando caótica a atuação de nosso sistema judiciário penal. Se prevalecer a prática

atual, talvez não possamos mais falar sequer em "sistema" ...

Rio, maio de 2016 